\title{
The Geopolitics of the Energy Transition
}




\section{About KAPSARC}

The King Abdullah Petroleum Studies and Research Center (KAPSARC) is a non-profit global institution dedicated to independent research into energy economics, policy, technology and the environment across all types of energy. KAPSARC's mandate is to advance the understanding of energy challenges and opportunities facing the world today and tomorrow, through unbiased, independent, and high-caliber research for the benefit of society. KAPSARC is located in Riyadh, Saudi Arabia.

This publication is also available in Arabic.

\section{Legal Notice}

(c) Copyright 2019 King Abdullah Petroleum Studies and Research Center ("KAPSARC"). This Document (and any information, data or materials contained therein) (the "Document") shall not be used without the proper attribution to KAPSARC. The Document shall not be reproduced, in whole or in part, without the written permission of KAPSARC. KAPSARC makes no warranty, representation or undertaking whether expressed or implied, nor does it assume any legal liability, whether direct or indirect, or responsibility for the accuracy, completeness, or usefulness of any information that contain in the Document. Nothing in the Document constitutes or shall be implied to constitute advice, recommendation or option. The views and opinions expressed in this publication are those of the authors and do not necessarily reflect the official views or position of KAPSARC. 


\section{Key Points}

The energy transition has major geopolitical implications.

Renewable energy could mitigate geopolitical tensions by mitigating climate change.

The energy transition could contribute to economic uncertainty in the Middle East and North Africa (MENA) region.

The speed of the energy transition is key to allowing producer economies to adapt.

The carbon intensity of different grades of crude could assume added importance over time.

The refining sector faces challenges as the industry comes under pressure to reduce its emissions. 


\section{Summary}

he energy transition is characterized by, among other things, a move away from

fossil fuels to other energy sources such as renewables, a process driven by the development of new technologies and declining costs. This transformational shift has geopolitical implications because renewables are fundamentally different from fossil fuels. While the latter are concentrated in specific geographical locations, renewables are dispersed and are mostly available in some form at the point of consumption. Supplies are harder to disrupt and, as a result, the choke points that have caused such geopolitical concern have become less relevant. However, as the energy transition gets underway, changing the economic dynamics that underpin many countries in politically volatile regions, it is clear that these new realities bring geopolitical risks.

In particular, the countries of the Middle East and North Africa (MENA) region are facing a period of uncertainty as climate change policies and technology advances lead to changes in the global energy mix and reduce the focus on hydrocarbons. However, oil will continue to be an important part of the energy mix for the foreseeable future, though most scenarios suggest that demand for it will slow. The speed of the energy transition is key to allowing resource-holding countries the time to adapt their economies to new realities and thus mitigate geopolitical risks.

With demand for oil falling, producers could embark on a fight for market share, potentially exacerbating geopolitical risks. Overall, the Gulf Cooperation Council (GCC) region is likely to come out well as regional oil producers embark on strategies aimed at highlighting variable carbon intensities $(\mathrm{Cl})$. There is a wide variety of $\mathrm{Cl}$ among different sources of crude oil, though quantifying such differences is complex. Moves to optimize crude sources through regulatory measures such as carbon border adjustment taxes could be challenging, though not impossible, to implement.

In consuming countries, notably in Europe, the refining sector is likely to struggle under the weight of increasingly stringent climate-related regulation. Even though the industry is key to securing energy supply, many refineries are at risk of closure in the longer run, especially those that are not vertically integrated or are in uncompetitive locations. 


\section{Background to the Workshop}

uring 2017, KAPSARC launched a new research initiative, focused on the role of fossil fuels, particularly petroleum, as the world transitions to a low-carbon future following the 21st meeting of the Conference of the Parties (COP 21) Paris Agreement. As part of this initiative, KAPSARC held a workshop in The Hague on April 19-20, 2017 with the Clingendael International Energy Program (CIEP), followed by another workshop in Riyadh on December 11, 2017. A subsequent workshop was jointly organized with the International Energy Forum (IEF) and held at its headquarters in Riyadh on February 15, 2018, and another was organized with the CIEP and held in The Hague on April 9, 2018. The most recent workshop was held on April 24, 2019, at Hus Clingendael in The Hague.

There is a growing awareness that the energy transition, with its wide range of impacts on consumer and producer countries, could impact geopolitics: Some regions are affected differently, trade flows change and previously key strategic relationships may be weakened. Previous workshops have focused on issues such as adaptive strategies in response to the energy transition. Though geopolitical impacts had previously been touched on, a decision was taken to focus this workshop entirely on the geopolitical impacts of the transition. Experts from a wide range of backgrounds attended it.

Key questions asked of the participants included:

Will the global balance of power be affected?

Where are geopolitical risks likely to emerge?

Will the energy transition weaken OPEC?

How can hydrocarbon producers with low upstream greenhouse gas emissions capitalize on this advantage to increase their market share?

Will past business models in consuming countries be adversely affected? 


\section{Geopolitics of Renewable Energy: Generating Impacts Beyond the Grid?}

s the speed and the pace of the energy
transition ramps up and the consequences
for resource holders, international oil companies, financiers and consumers become increasingly clear, analysts are beginning to focus their attention on the wider geopolitical impacts of the transition. International organizations such as the International Renewable Energy Agency suggest that we are on the cusp of a transition from fossil fuels to renewables, a process driven by new technologies and declining costs.

This transformational shift has geopolitical implications because renewables are fundamentally different from fossil fuels. While the latter are concentrated in specific geographical locations, renewables are dispersed and are mostly available in some form at the point of consumption. Since renewables take the form of flows - wind, water and/or sun - rather than stocks, they cannot be exhausted and are hard to disrupt.

The rapid growth of renewable energy is likely to lead to a global power shift, with losers likely to be high-cost resource holders highly dependent on exports, such as Angola, Nigeria and Venezuela. Such countries will come under pressure to rapidly diversify their economies. The winners will be fossil fuel importers that can switch to domestic renewable energy sources, leading to improved trade balances and increased foreign policy autonomy. Countries that are best placed to gain under this scenario include Chile and Australia. These countries have a high technical potential for renewable energy that could be harnessed to produce hydrogen, enabling them to become net exporters of energy. Other winners could be mineral-rich countries such as Bolivia and Mongolia. A key potential beneficiary could be China - currently leading the race toward clean energy - which, in addition to improving the cleanliness of its domestic energy industry and air quality, could win from the export of renewables technologies. It is currently the biggest producer and exporter of solar panels, wind turbines, batteries and electric vehicles. However, inversely, it is also a major exporter of coal plants and a major user of coal for power generation, and the wholesale abandonment of coal would come at great cost to the country. And, in a world of increasing trade tensions and concern from the United States that China is winning the technological race, it is likely that the world will not accept a monopoly on these technologies. The current saga over Huawei might be a precursor of what is to come.

Renewable energy will create new trade patterns, with a shift away from global fuel markets to regional power grids. As a result, global choke points could become less significant, and political alliances based on oil security weakened, which could impact arms sales and military-based policies. Energy statecraft could change, reducing the use of oil as a geopolitical instrument and altering the global landscape of conflict. Materials critical to renewable energy will gain in significance but are unlikely to pose the same geopolitical risks or carry the same strategic importance as oil and gas. However, legacy hydrocarbon producers are likely to fight back in a bid to maintain energy market share. This can be done by embarking on decarbonization strategies such as producing green hydrogen that is decarbonized by capturing the carbon at source and storing it in geological reservoirs. Security concerns will center on cybersecurity and access to minerals, with countries such as the Democratic Republic of Congo playing an oversized geopolitical role due to the world's dependence on cobalt, of which it is the world's biggest producer, not to mention China with its dominance in rare earth minerals. 
The energy transition and the rise of renewables bring with them the potential for domestic instability and social dislocation as traditional sectors such as coal lose out. Likewise, high-cost oil and natural gas producers that see their income from exports decline will have a hard time sustaining their existing social models.
On the upside, renewables have the potential to mitigate climate change, which is widely regarded as a global security threat. Some countries could leapfrog others in their economic development by developing off-grid energy networks without the need to invest in mega infrastructure projects. Though as the energy transition gets underway, it is clear it brings geopolitical risks, too, as countries face up to the new realities. 


\section{Geopolitical Challenges of the Energy Transition to MENA Oil Producing Countries}

$\mathbf{F}$ or some, the global energy transition represents a two-way street: changes to the global energy landscape are shaping the political and economic outcomes of the MENA region, while at the same time developments in key Middle East oil producing countries influence the speed of the energy transition. The MENA region is important not only because of its reserves, production and exports, but because it has also witnessed some of the largest output variability, with implications for oil prices and oil market outcomes.

MENA countries face a period of uncertainty as climate change policies and technologies advance, particularly in the transportation sector, increasing the range and speed of the potential outcomes. The range of uncertainty is high and projections -or scenarios - are highly sensitive to underlying assumptions such as gross domestic product, population, efficiency gains, carbon pricing and the interactions of various technologies. There is also the possibility of multiple peaks caused by rebound effects, with a potential peak in oil demand causing oil prices to fall, and consequently triggering higher demand from consumers. However, oil will continue to be an important part of the energy mix for the foreseeable future, though most scenarios suggest growth in demand for it will slow. Even though economic history shows that rapid global transitions rarely take place, the possibility of a fast transition cannot be entirely discounted.

The speed of the energy transition is key, as a slower transition will allow impacted economies to adapt, but it is highly uncertain. Furthermore, even though the impacts are already beginning to be visible across the globe, they are distributed unevenly. It is widely accepted that there is no such thing as a smooth transition and that the MENA region is in for a bumpy ride. Depriving states of their income will inevitably lead to geopolitical instability.

Regardless of the speed of the transition, there is already a change in the perceptions and behavior of MENA oil producers. The transition brings a new context to the domestic discussion around the need for economic diversification. For major resource holders, it raises key questions such as the future value of oil in the ground. Selling oil forward in order to diversify asset bases and income has become a policy option, and the proposed initial public offering of Saudi Aramco should be seen in this light.

Governments will come under growing pressure to implement economic reforms so as to adjust to a lower price environment and to diversify countries' economic bases and income streams.

In the short term, oil policies are likely to be affected. It is often argued that producers have an incentive to monetize reserves now by lifting oil out of the ground as soon as possible. This should, in theory, lead to a 'rational policy' under which oil producers pursue a high output, low price strategy. In this context, cooperation between producers to balance the market becomes more challenging as competition between them intensifies.

In reality, producers are likely to continue to cooperate to restrict - or increase - output as market conditions dictate, though such alliances will become more difficult over time as demand growth slows. Such a policy comes at a cost: keeping prices high will accelerate demand reduction and boost the emergence of new sources of supply. However, the alternative of pursuing competition at any price is very costly. Clearly, MENA oil policymakers are caught between a rock and a hard place. 


\section{The Speed of the Energy Transition is Key}

$\mathbf{T}$

The speed of the energy transition is key to allowing resource-holding countries the time to adapt their economies to the new realities and thus to mitigate geopolitical risks. Transportation sector demand is a key element that will dictate the pace of change in the global energy mix. Subsidies in consumer countries aimed at jump-starting the market for electric vehicles (EVs) have already begun to taper off in many countries. China now appears to be hedging its technological bets by subsidizing hydrogen, which, if it takes off as a transportation fuel, could provide a lifeline to crude oil demand. Demand for energy-intensive goods and services from emerging markets is likely to grow, be it for air conditioning, flights or cars. In India, 300 million people are expected to take at least one flight a year by 2040. Continued oil demand growth is being mitigated by heavy spending on renewables and energy efficiency, led by China. There are already 450 million smart meters in Chinese homes.

Supporters of the internal combustion engine are fighting back, aiming to reduce carbon emissions through a number of incremental efficiency improvements in both engine technology and fuel composition. Demand for passenger vehicles continues to increase, with 200 million new cars joining the world total over the last eight years, and there is strong demand for heavy goods vehicles, particularly in Asia.

EV growth is being held back by concerns about the resale value of such vehicles. There is also a growing realization that lifecycle emissions from EVs, which have the high upfront carbon tag associated with batteries, mean that they might not be as good for the environment as originally believed, especially if the source of the electric power is not clean.

A further boost to oil could potentially come from another unexpected quarter, namely clean cooking in the developing world. A total of 3 billion people are estimated to lack access to clean cooking fuel, an issue being increasingly addressed by governments and multilateral agencies. Liquefied petroleum gas (LPG) is an obvious fuel source and, in recent years, the Indian government has provided LPG to 70 million homes representing around 250 million people. Despite its carbon emissions, LPG remains an easy option for governments seeking to supply low-income homes, currently dependent on biomass, with clean cooking. 


\section{Oil Producers Fight for Market Share \\ by Highlighting Their Low-Carbon \\ Credentials}

$\mathbf{W}$

inners and losers will appear in the fight for market share, potentially exacerbating geopolitical risks. Overall, the Gulf Cooperation Council (GCC) region is likely to do well as regional oil producers embark on strategies aimed at highlighting variable carbon intensities $(\mathrm{Cl})$. $\mathrm{Cl}$ varies widely among different sources of crude oil, though quantifying such differences is complex. In addition, moves to optimize crude sources through regulatory measures such as carbon border adjustment taxes could be challenging, though not impossible, to implement.

As the market starts to account for these differences through price, consumer preference, or some other mechanism, $\mathrm{Cl}$ will become another competitive element that can be leveraged by producers. The strategies that could emerge from this new situation will likely fall into four major categories: portfolio management, operations improvements, offsets, and product/service differentiation.

The simplest strategy for a producer is to adjust its portfolio of resources and consumers. Shifting focus toward existing low $\mathrm{Cl}$ resources or acquiring new assets overseas can improve a producer's competitiveness in this respect. On the consumer side, depending on the $\mathrm{Cl}$ of its portfolio, a producer may target different markets with different strategies. For Europe and other locations that have a strong preference for low $\mathrm{Cl}$, low $\mathrm{Cl}$ crude can be sold at a premium. For energy starved markets with less preference for low $\mathrm{Cl}$, high $\mathrm{Cl}$ crude can be sold at a volume discount. This second strategy might be an unfortunate but entirely predictable outcome of imperfect regulatory coverage.
Operations, while a small emissions source compared with end use, are controllable by operators. Improved practices for venting, flaring, and dealing with fugitive emissions have the most direct impact, and can even be monetized in many cases. Additional options include more efficient designs for new assets, and techniques that improve recovery from existing resources.

Offsets directly reduce $\mathrm{Cl}$ by adding negative emissions factors. The primary source of carbon in a barrel of oil (and oil products) is in the oil itself, which is released when burned to generate energy. In addition, there are the emissions from operations, transportation and refining. For many reservoirs around the world, carbon dioxide (CO2) can be injected directly into the reservoir to stimulate oil production in a process known as enhanced oil recovery (EOR). Typical CO2-EOR operations use a minimum quantity of $\mathrm{CO} 2$ to generate more oil production, but much more can be injected if the priority shifts to include carbon storage as a benefit. For many reservoirs, the net outcome is a carbon neutral or even carbon negative barrel of oil. One challenge to implementing this option is the cost of capture and transport of $\mathrm{CO} 2$ to oilfields. Many operators would gladly use CO2-EOR if the $\mathrm{CO} 2$ were cheap enough. Regulatory mechanisms under the Paris Agreement could solve this issue by rewarding successful carbon sequestration with credits that could defray these costs.

Lastly, low $\mathrm{Cl}$ services and products can diversify the offerings of the producers. Carbon sequestration services could add another revenue stream if $\mathrm{CO} 2$ can be imported from consumer nations. Low energy costs and nearby carbon 
storage options may attract industries like steel and cement manufacturers, generating more local employment. Non-combustible (hence non-emissions producing) products like chemicals show promise as significant drivers of future demand growth, and fully decarbonized fuels like hydrogen and ammonia also have demand growth potential when derived from hydrocarbons with carbon capture and storage (CCS). 


\section{Carbon Strategies: European Refineries Fight Back}

o establish a global geopolitical energy balance, regions need to maintain energy security across the hydrocarbon value chain. Dependence on crude imports might be inescapable for some countries, but an important reliance on refined products adds another layer of geopolitical insecurity. Seen in this context, the refining industry's significance is more than purely commercial, not least in Europe, with its large number of refineries. There are 82 refineries in the European Union plus Norway and Switzerland. The size of these refineries is relatively small compared with newer refineries in the Middle East and India. In recent years, competition from export refineries in other regions has led to a wave of refinery closures in the European Union (EU).

There are four types of refineries in Europe: coastal and inland refineries, and integrated and stand-alone refineries. These four are important for the potential survival of refineries when $\mathrm{CO} 2$ emissions have to be reduced to $80 \%$ or more compared with 1990 levels to meet EU strategies. In general, integrated refineries have more options to improve energy and carbon efficiency than non-integrated and standalone refineries.

The International Energy Agency projects EU oil demand will decline, creating further pressure on refineries. This comes on top of increased imports and higher costs associated with climate change mitigation measures. As a result, only the most efficient refineries will be able to withstand the changed business and policy environment. In Northwest Europe, most refineries are export oriented and already exposed to imports. A total of 12 out of 34 refineries are fully integrated with petrochemicals, meaning that the refinery must always run in order to feed the downstream units. Another nine refineries are closure constrained for other reasons, such as the need to deliver heat to nearby towns or delivering products to captive clients, while 13 refineries are fully exposed to competition, with few alternative strategies available, and are therefore less able to withstand both competitive and policy pressures.

Of the various refinery centers, the AntwerpRotterdam and Rhine-Ruhr clusters have the largest and most integrated refineries.

Integrated refineries are often fully integrated with petrochemical industries and, in some cases, with heat markets. With more renewable energy (electricity and hydrogen) expected to enter the market, refineries can be a natural market for renewable energy producers to electrify certain refining processes. As a result, they can deliver cleaner products for the transportation sector and other markets. Depending on the geology or location of the refinery, CCS could be one option to lower its carbon footprint. With their long investment cycles, Europe's refineries and petrochemical industries need to understand the direction of energy and climate policy-making; they will need to invest in new infrastructure both internally and externally to achieve higher energy and carbon efficiencies. If a single EU country decides to price $\mathrm{CO} 2$ above the EU Emissions Trading Scheme level in order to achieve faster emissions reductions, then it could be argued that national companies affected by such policies should be compensated for this by their governments in order to maintain a level playing field in the EU. 


\section{About the Workshop}

tarting in 2017, KAPSARC and the Clingendael International Energy Program

(CIEP) have convened a series of workshops on the Role of Oil in the Low Carbon Energy Transition. This workshop held on April 25th, 2019 took place in Hus Clingendael, The Hague, under a modified version of the Chatham House Rule under which participants consented to be listed. However, none of the content in this briefing can be attributed to any individual attendee.

\section{List of participants}

Adam Sieminski - President, KAPSARC

Paul Mollet - Research Fellow, KAPSARC

Colin Ward - Research Fellow, KAPSARC

Eric Williams - Research Fellow, KAPSARC

Coby van der Linde - Director, Clingendael International Energy Program

Pier Stapersma - Researcher, Clingendael International Energy Program

Luca Franza - Researcher, Clingendael International Energy Program

Fahad Alidi - Saudi Aramco Fellow at the World Economic Forum (WEF)

H.E. Dr. Majid Al-Moneef - Kingdom of Saudi Arabia Royal Court

Sverre Alvik - Programme Director, Energy Transition, DNV GL - Group Technology and Research

Eaman Aman - Advisor, Ministry of Energy, Industry and Mineral Resources (MEIM)

Kamil Ben Naceur - Chief Economist, ADNOC

Kingsmill Bond - New Energy Strategist, Carbon Tracker

Chen Weidong - President, Mind Institute
Joel Couse - Chief Energy Economist, Total

Bassam Fattouh - Director, Oxford Institute for Energy Studies (OIES)

Antoine Halff - Director, Global Oil Markets, Columbia University

Glada Lahn - Senior Research Fellow, Chatham House

Chris Malins - Consultant, Cerulogy

Andre Marcu - Senior Fellow, International Centre for Trade and Sustainable Development (ICTSD)

Julien Perez - Strategy and Policy Director, OGCI Investments

Christof Rühl - Consultant

Paul Stevens - Distinguished Fellow, Chatham House

Matthew Jurecky - VP Market Intelligence, Mubadala Petroleum \& Petrochemicals

Thijs van de Graaf - Professor, University of Ghent

Aleksei Belogorev - Deputy Principal Director on Energy Studies Institute for Energy and Finance

Pierre-Olivier Calendini - Saudi Aramco

Patrick Gaillard - Saudi Aramco

Hari Dattatreya - Global Oil Director, Royal Vopak

Maurits Kreijkes - Oil Markets Analyst, Strategic Oil Reserve Authority

Michael Traver - Saudi Aramco

Wim Thomas - Chief Energy Advisor / Head Energy Team, Shell International B.V.

Wijnand Tutuarima - CFO, Heerma

Frank van Oordt - Fellow, World Bank 


\section{About the team}

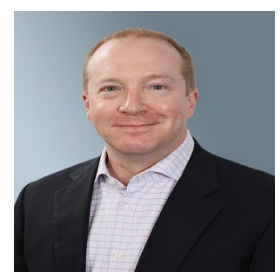

\section{Brian Efird}

Dr. Efird is Program Director for Policy and Decision Science at KAPSARC, where he manages a research portfolio covering a global program of work focused on energy policy and the nexus between geopolitics and energy economics. This program encompasses a multi-disciplinary, multi-national team of researchers who focus on quantitative models of collective decision-making processes (CDMPs), geospatial information system applications to energy economics and energy policy, and the impact of political phenomena on global energy markets. Dr. Efird is Co-Editor-in-Chief of Energy Transitions, an open access journal from Springer Scientific.

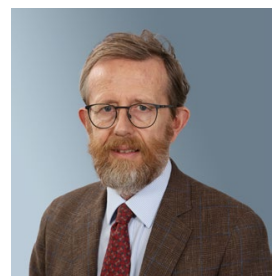

\section{Paul Mollet}

Paul was a research fellow in the Policy and Decision Sciences program. He is a former journalist and energy market analyst with over 25 years of experience in international energy markets. He opened the first Gulf Cooperation Council bureau for the oil price reporting agency S\&P Global Platts in Dubai in 1989 and later launched the first regional office for Argus Media. Paul has attended numerous OPEC meetings and written extensively about the oil industry in publications such as Platts Oilgram News, Argus Global Markets, and the Petroleum Economist. He was also the senior advisor to the Secretary-General at the World Energy Council (WEC).

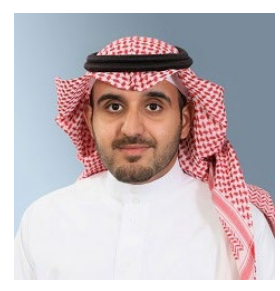

\section{Saleh Al-Muhanna}

Saleh is a senior research analyst in the Policy and Decision Science program. His interests lie in geopolitical research, international agreements and international trade. Saleh holds a master's degree in international commerce and policy from George Mason University and a B.S. degree in economics from Pennsylvania State University.

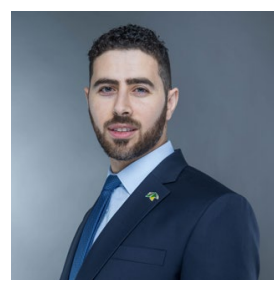

\section{Abdelrahman Muhsen}

Abdelrahman is a senior research associate in the Policy and Decision Science program. $\mathrm{He}$ is a certified GIS Professional (GISP) with years of industry and research experience in GIS and spatial analytics. Previously, while working for Accenture and independently, Abdelrahman utilized system design strategies and enterprise architecture principles to help several clients in the oil and gas industry design, implement and realize the full value of their WebGIS platform and spatial data repositories.

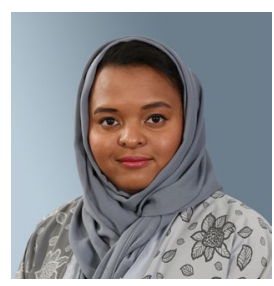

\section{Lama Yaseen}

Lama is a software developer and a Research Associate at KAPSARC's Policy and Decision Science program. She is currently the lead developer and the project manager of the KAPSARC Toolkit for Behavioral Analysis (KTAB). Lama has also worked in various research projects examining renewable energy policies in the GCC and developing projects in energy access and humanitarian assistance missions. Lama is currently pursuing her M.Sc. in software engineering at the University of Oxford, focusing on data-driven software development. 


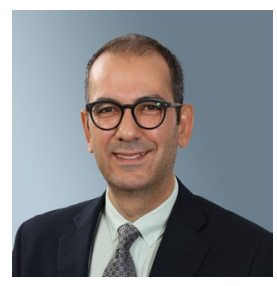

\section{Mehmet Soytas}

Dr. Soytas is currently a researcher at KAPSARC. His research covers topics in labor economics and firm sustainability and strategic behavior at large. He models economic decision-making processes of individuals, households and firms using dynamic programing techniques and applied game theory. He has authored numerous articles in the fields of labor economics, economic policy, econometrics, and corporate sustainability. He previously worked as a consultant for the World Bank and Energy Exchange Istanbul, and as an Associate Professor of Economics at Ozyegin University. Dr. Soytas holds a Ph.D. in economics from the University of Pittsburgh.

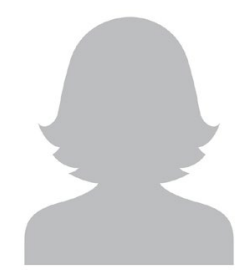

\section{Nourah Al Hosain}

Nourah is a research analyst in KAPSARC's Policy and Decision Science program. She is currently working with the KAPSARC Toolkit for Behavioral Analysis (KTAB) development team. She holds a B.S. degree in computer science from Prince Sultan University.

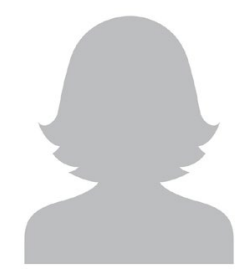

\section{AlJawhara Al Quayid}

Aljawhara is a senior research analyst in the Policy and Decision Science program with research interests in political economy, international affairs, finance and trade. She holds a B.Sc. in business administration, with a focus in finance, from Alfaisal University, Riyadh.

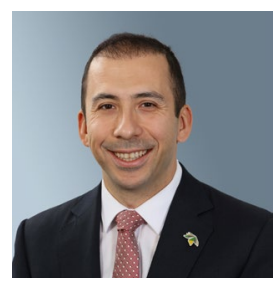

\section{Emre Hatipoglu}

Dr. Hatipoglu is a research fellow at KAPSARC and Associate Professor of Political Science at Sabanci University. His research interests cover energy and geopolitics, comparative foreign policy, international conflict, and social media and politics. Dr. Hatipoglu's work has been published in the Journal of Politics, Foreign Policy Analysis and Defence and Peace Economics, among others. Dr. Hatipoglu holds a Ph.D. in political science from Penn State University.

\section{About the Project}

This workshop took place as part of the Geopolitics and Energy Markets project, which aims to integrate insights, methods and approaches from the field of political science to better understand energy market behavior. 
INAPSARC

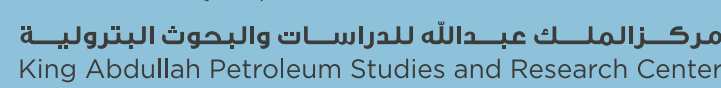

www.kapsarc.org 